\title{
Processo comunicativo e humanização em saúde
}

Suely Ferreira Deslandes ${ }^{1}$

Rosa Maria de Araujo Mitre ${ }^{2}$

DESLANDES, S.F.; MITRE, R.M.A. Communicative process and humanization in

healthcare. Interface - Comunic., Saude, Educ., v.13, supl.1, p.641-9, 2009.

This paper deals with the communication process as one of the challenges to be faced in humanizing healthcare. The potential and requirements for the production of communicative action are discussed, and certain obstacles are indicated, based on anthropological studies on biomedical culture. Using the concept of understanding, the paper discusses healthcare encounters and the relevance of validation and recognition of different players' discourse. It indicates the importance of taking a relative view of identity marks associated with biomedical culture, deconstructing certain concepts, criticizing their contexts of applicability and even proposing new marks through humanization. The relationship between biomedical technologies and the communication process is discussed. The challenge put forward is to learn, recognize and negotiate with others who have their own particular rights, autonomy and cultural baggage. Finally, the paper discusses the theoretical efforts towards making humanization of healthcare practices part of the ethos or worldview of healthcare professionals.

Keywords: Humanization of care. Communication. Comprehension. Healthcare.
O artigo aborda o processo

comunicacional como um dos desafios enfrentados na humanização em saúde. Reflete sobre potencialidades e requisitos para a produção do agir comunicativo e aponta alguns obstáculos, baseando-se em estudos antropológicos sobre a cultura biomédica. Com base no conceito de entendimento, discute sobre os encontros em saúde e a relevância da validação e do reconhecimento do discurso dos diferentes atores. Aponta para a importância de se relativizarem marcas identitárias associadas à cultura biomédica, desconstruírem-se alguns conceitos, criticarem seus contextos de aplicabilidade e até mesmo se propor novas marcas por meio da humanização. Discute-se a relação entre as tecnologias biomédicas e o processo comunicacional. O desafio colocado é o de aprender, reconhecer e negociar com o outro, que detém direitos, autonomia e estoque cultural peculiares. Finalmente, discute os esforços teóricos para que a humanização das práticas em saúde venha a fazer parte do ethos ou visão do mundo dos profissionais de saúde.

Palavras-chave: Humanização da assistência. Comunicação. Compreensão. Saúde.

\footnotetext{
1 Departamento de Ensino, Instituto Fernandes Figueira, Fundação Oswaldo Cruz (IFF/Fiocruz). Av. Rui Barbosa, $716,2^{\circ}$ andar. Flamengo, Rio de Janeiro, RJ, Brasil. 22.250-020 desland@iff.fiocruz.br

${ }^{2}$ Departamento de Pediatria, IFF/Fiocruz.
} 


\section{Introdução}

Quando autores da área de Saúde Coletiva tratam da temática de humanização, reconhecem estar diante de um imperativo ético-institucional e um princípio instituinte do Sistema Único de Saúde (SUS). Ninguém duvida em adjetivar como cuidado de qualidade aquele que tem as premissas orientadoras de ser integral, universal, equitativo e humanizado. O conceito de humanização já conta com um acúmulo de representações no campo de saúde. Primeiramente, foi entendido, por muitos atores envolvidos no processo de saúde, como uma possível acusação unilateral e culpabilizante de maus-tratos ao usuário; a seguir, o conceito ultrapassou a noção de caritas e, hoje, ousamos dizer que já enfrenta certo processo de banalização dos desafios que ele anuncia (e, consequentemente, esvaziamento).

A definição de humanização atualmente adotada no campo da saúde inclui os parâmetros definidos pela Política Nacional de Humanização - PNH (Brasil, 2004). Entende-se a proposta de humanização como um conjunto de princípios e diretrizes que afirma a valorização dos diferentes sujeitos implicados no processo de produção de saúde (usuários, trabalhadores e gestores); o fomento da autonomia e do protagonismo desses sujeitos; o aumento do grau de corresponsabilidade na produção de saúde e de sujeitos; o estabelecimento de vínculos solidários e de participação coletiva no processo de gestão; a identificação das necessidades sociais de saúde, dos usuários e dos trabalhadores; e o compromisso com a ambiência, com a melhoria das condições de trabalho e de atendimento. O debate de humanização produzido pelos autores brasileiros vai enfocar, entre tantos aspectos e desafios, as dimensões éticas do cuidado, a importância da comunicação e do diálogo para projetos terapêuticos comprometidos com a vida e os direitos dos usuários (Ayres, 2004; Deslandes, 2004; Fortes, 2004).

Destes consideráveis desafios, destacamos o de ordem comunicacional. Por processos comunicacionais não nos referimos ao sucesso de emissão e compreensão de um conteúdo informativo. Falamos de um processo muito mais amplo que nos constitui como seres humanos, porque seres sociais de linguagem, capazes então de denotar/conotar, explicar/confundir, autorizar/desautorizar, consentir/ proibir (Gadamer, 1997; Habermas, 1989, 1987). Um processo pelo qual podemos construir e atualizar novas versões do mundo, do sofrimento, do cuidado e de nós mesmos.

Quando nos referimos a processo comunicacional, nos remetemos à possibilidade de produzir entendimento por meio do diálogo, dos atos de fala cotidianos que acontecem nas relações face a face. E esta competência é estratégica para a produção do cuidado em saúde e, também, para a gestão, comprometidos com a humanização.

Ao falarmos do processo comunicacional no contexto da humanização, nos referimos à expansão de uma competência comunicativa que constitui a base de um cuidado e gestão emancipadores, onde os diferentes atores desse cenário possam se reconhecer e se implicar.

O presente texto constitui um ensaio teórico que busca discorrer sobre as potencialidades e requisitos para a produção deste agir comunicativo. Para isso, recorreremos à leitura filosófica de Habermas e depois, com o apoio da leitura sociológica (a crítica de Pierre Bourdieu, 1996) e de alguns estudos socioantropológicos (Thompson, 2000; Hoas, 1999; Strauss et al., 1963), apontaremos obstáculos e possibilidades à produção comunicativa voltada ao entendimento no contexto do cuidado em saúde. Num segundo momento, discutiremos o que consideramos falácias a respeito do uso de tecnologia como elemento desfavorável ao processo comunicacional e debateremos outras tecnologias destinadas à produção de entendimento.

\section{Entendimento e razão comunicativa}

Destacamos a proposta habermasiana do agir comunicativo, que, como se verá adiante, está estreitamente associada a diversos princípios da humanização, tais como: valorização da dimensão subjetiva e social nas práticas de atenção e gestão no SUS; construção de redes comprometidas com a produção de saúde e com a produção de sujeitos; construção de autonomia e protagonismo dos sujeitos e coletivos implicados na produção dos cuidados de saúde; e corresponsabilidade desses sujeitos nos processos de gestão e atenção (Brasil, 2004). 
Habermas irá criticar as bases da racionalidade moderna, uma racionalidade instrumental que historicamente identificou, como finalidade do conhecimento, a intervenção e normatização, numa síntese de conhecer para dominar. Uma racionalidade, portanto, voltada pragmaticamente para o domínio e incapaz de viabilizar a emancipação humana (Habermas, 1990a, 1990b).

Este autor irá propor outra racionalidade, ancorada na comunicação e em processos amplos de argumentação de onde serão construídas as validades dos discursos e das ações.

Assim, a razão comunicativa não se constrói apenas logicamente, mas, antes de tudo, na processualidade do debate. Envolve decisões existenciais, um agir no mundo e uma ética de solidariedade contra o sofrimento e a opressão. Situa-se como um modelo político em que a práxis e a palavra estão em profunda sinergia.

Para iniciar nossa reflexão, nos remetemos ao conceito de entendimento visto como um processo comunicativo voltado para a produção de um consenso. O entendimento refere-se, portanto, não ao consenso em si ou aos seus conteúdos (que podem ser transitórios), mas à disposição e dispositivos empregados para sua produção.

A comunicação que busca o consenso se baseia numa troca ativa e pacífica de informações entre participantes de uma certa prática social, ancorada em estruturas racionais. Esse entendimento seria produzido internamente, e não a partir de um a priori fixo, precisando ser aceito como válido pelos participantes da comunicação. Falamos de um consenso possível.

Siebeneichler, estudioso de Habermas, vai definir entendimento como um processo que:

[...] abrange uma série encadeada de atos de fala. Neste contexto o ato de fala de um participante somente tem sucesso se o outro participante aceitar a oferta contida neste ato, dizendo "sim" ou "não". Isso significa que, tanto o primeiro falante, que levanta, através de seu proferimento, uma pretensão de validade, como o segundo falante, que reconhece ou rejeita esta pretensão, apóiam suas decisões em algum tipo de razão ou argumento.

(Siebeneichler, 1994, p.95)

Esta definição retrata o encontro entre dois ou mais sujeitos, que, mesmo com capitais distintos, têm sua fala reconhecida como válida. Nota-se que não se busca uma ingênua e imediata concordância de opiniões, mas trata-se aí do reconhecimento de ambas as falas, da capacidade de aceitar ou discordar, visto que se apoiam em argumentos válidos. Adequado para se pensar o encontro entre terapeuta e pessoa doente, ou entre trabalhadores de uma equipe de saúde, ou, ainda, entre profissional e gestor. Capitais distintos de conhecimento (técnicos e vivenciais), mas que não levam ao emudecer de um diante do outro. Ao contrário, a diversidade de argumentos é exatamente fomentadora deste encontro, agregando mais legitimidade e riqueza ao entendimento. Trata-se de um consenso voltado à afirmação da vida.

Entretanto, este é um notável desafio: reconhecer a fala do outro como válida. Posto em outros termos, se a fala do outro é desqualificada, não reconhecida, ou seus argumentos são sequer colocados, não há nenhuma hipótese de entendimento ou ação comunicativa emancipadora.

A validade dos argumentos estaria baseada em algumas pretensões reconhecidas: de inteligibilidade da mensagem contida; de verdade do conteúdo proposicional; de correção, de justeza em face do mundo social; de sinceridade na ordem subjetiva.

Todavia, para reconhecer o argumento do outro como válido, torna-se mister a adoção de uma postura interpretativa, uma busca de conhecimento-tradução dos referentes e contextos do mundo da vida deste outro autor, pressupondo aí o reconhecimento de sua racionalidade. Implica, enfim, buscar conhecer as situações que levaram o autor a enunciar aquele texto. Em outros termos, demanda um exercício hermenêutico.

Exercício este que depende de uma compreensão "correta" do discurso do outro (Schleiermacher, 1999), o que envolve um processo ativo, de construção e busca de significados e interpretações (Caprara e Franco, 2006) e que, por conta desta característica processual contínua, terá sempre limitações (Ayres, 2005). 
Habermas (1989) vai postular que, numa situação de fala ideal, não existe a possibilidade de coação da fala do outro, mas o confronto de argumentos, ancorados em postulados que falam da igualdade dos participantes em argumentar, interpretar, recomendar, justificar, explicar, baseados na veracidade e sinceridade. Estas condições são reconhecidas pelo próprio autor como inexistentes, mas funcionariam como um horizonte, um telos, uma utopia norteadora.

\section{Questionamentos sobre o agir comunicativo}

A proposta do agir comunicativo, entretanto, também tem sido historicamente alvo de questionamentos. O mais expressivo foi feito pelo sociólogo Pierre Bourdieu (1996) que criticou o suposto poder das palavras, da força ilocucionária e propositiva das expressões para a construção ativa de novos significados e consensos.

Para ele, os poderes da linguagem, da eficácia da palavra, da maneira ou do conteúdo do discurso dependem crucialmente da posição social dos interlocutores. Dependem do reconhecimento de uma autoridade, de um capital simbólico acumulado por certo grupo e enunciado por seus porta-vozes autorizados.

Bourdieu (1996) retrata, assim, as desigualdades presentes nas trocas comunicativas, afirmando que sua eficácia simbólica não se constrói no encontro entre falantes, mas se situa num conjunto de fatores que o antecede (a relação entre as propriedades do discurso, as propriedades daquele que o pronuncia e as propriedades da instituição que o autoriza a pronunciá-lo).

Tal debate nos ajuda a questionar as desigualdades presentes há séculos na cultura médica profissional entre seus agentes e seus pacientes. Mediando e mesmo dando as regras que estruturam o singular e criador encontro entre intersubjetividades, existe um grupo de posições, concepções, argumentos e falas considerados legítimos e autorizados, e outro grupo ainda relegado a um lugar de desqualificação. Da mesma forma que tais diferenças escalonam um patamar de hierarquias das falas de distintas classes profissionais.

No cotidiano das ações em saúde, marcadas pelo encontro - ou, muitas vezes, desencontro - dos diferentes atores, sejam estes usuários, profissionais ou gestores e seus saberes, o processo comunicativo acontece no contexto das relações preestabelecidas por modelos de assistência cristalizados e acriticamente reproduzidos. Estas ações são diretamente influenciadas tanto pelo contexto onde ocorrem, quanto pelos valores dos grupos sociais aos quais cada membro está vinculado, o que pode gerar distorções como, por exemplo, a supressão da mutualidade, característica implícita em um processo relacional (Caprara, Franco, 2006).

Ao levar em conta a crítica aos limites da proposta do agir comunicativo, cabe lembrar que não é possível pensar estaticamente no distinto capital já acumulado entre os agentes autorizados presentes no ato da produção do cuidado em saúde. Outrossim, hoje se verificam redes discursivas (sobre os direitos em saúde, de demandas de grupos de usuários que possuem uma identidade forjada por viver com certa patologia e, mesmo, sobre a humanização da atenção, entre outras) que ampliam paulatinamente os capitais dos usuários.

É certo também que as relações sociais envolvem sempre a possibilidade de reorganização dos padrões vigentes, de um vir-a-ser distinto a partir de novas ações e problematizações dos sujeitos.

Seguramente, ao lado deste modelo nucleador produtor de desigualdades, existem 'fissuras', certa flexibilidade mais ou menos elástica de negociação da ordem. Sem estas maleabilidades, a ordem hospitalar seria insuportável aos seus agentes e usuários. A teoria da ordem negociada nos aponta os muitos mecanismos de atualização, interpretação e uso peculiar das regras pelos diferentes agentes da ordem médica (Thompson, 2000; Hoas, 1999; Strauss et al., 1963).

Na prática, podemos ver isto por meio de algumas estratégias e dispositivos, alguns da própria PNH (Brasil, 2004), utilizados para subverter esta ordem e o modelo de atenção que dela deriva. No entanto, tais exemplos não podem e não devem ser tomados como prescrições capazes de gerar mudanças efetivas apenas por sua implantação. Servem, outrossim, como inspirações, fonte de aprendizado para novas experiências genuínas. 
Inequívoco dizer que a proposta de entender a produção de cuidados assistenciais em saúde a partir de uma racionalidade comunicativa estabelece uma outra ordem de referências. Contudo, pressupõe concordando em boa parte com a crítica de Bourdieu - uma relação minimamente simétrica entre falantes que estão em condições de compartilhar a construção de significados/entendimento. Demandam, assim, intenso investimento numa outra ordem de gestão, tanto do processo organizacional, quanto da gestão dos encontros intersubjetivos que dizem respeito aos cuidados em saúde.

Não se fala aqui de igualitarismos. Há que se reconhecer a diferença entre capital de conhecimentos científicos para decisões clínicas e outros capitais de conhecimentos e demais capitais simbólicos fundamentais para as decisões da vida, do cotidiano. A decisão por indicar esta ou aquela terapêutica diz respeito a um conjunto de conhecimentos acumulados e disponíveis aos agentes de um determinado campo científico. Por outro lado, a adesão ou não à referida terapêutica, por exemplo, constitui uma decisão única de um paciente conjugada às influências de sua rede familiar e social ampliada. Pode-se dizer que existem diferentes e antagônicos projetos terapêuticos em disputa e, também, a possibilidade em aberto da construção de um projeto terapêutico comum, que seja capaz de fazer sentido para os sujeitos nele envolvidos, ganhando o significado de compromisso com a vida. (Ayres, 2004).

O compartilhamento, a construção intersubjetiva de entendimentos no/e pelo processo comunicativo podem (e devem) funcionar como horizontes da práxis em saúde, concretizáveis a partir de profundos e sistemáticos investimentos críticos na formação contínua do profissional de saúde, em modelos favoráveis de gestão, e na ampla politização do estatuto de sujeito do usuário e do profissional. Mas não está espontaneamente dado pela singularidade do encontro intersubjetivo per si. Embora seja nele que, efetivamente, se realize. Ousaríamos dizer que o encontro do cuidador com a pessoa que sofre certo agravo demanda um interesse ativo pelo outro. E esta atitude de verdadeiro interesse por sua história, por sua constelação de motivações, aspirações e expectativas pode favorecer um entendimento provisório e renovável.

Assim, ao buscarmos produzir uma leitura aberta e inclusiva, propositora e mediadora de mudanças, também somos desafiados a rever o que em nossas identidades se define pela extrema violência simbólica de tornar o Outro invisível ou ilegítimo em suas necessidades e expressões (Deslandes, 2004). É falar das dificuldades das trocas intersubjetivas nos serviços de saúde e de problematizar as relações de poder que envolvem a legitimidade ou ilegitimidade atribuída a esta ou aquela narrativa/versão de como são as coisas, o trabalho, o cuidado e mesmo o sofrimento.

\section{Humanização como elemento de ethos e de visão de mundo}

Uma outra ordem de questionamentos sobre a ação comunicativa advém dos estudos antropológicos que se debruçam sobre a cultura biomédica e suas marcas de identidade.

Numa perspectiva antropológica contemporânea, o termo ethos tem sido amplamente utilizado para designar acervo de valores caros a um grupo e que lhe define uma certa identidade. Assim, por exemplo, seus usos podem variar desde estudos sobre ethos religiosos, profissionais, étnicos etc (Ferreira, 2007; Graeff, 2006).

Geertz (1989) designa que o ethos de um grupo ou sociedade assinala um valor moral e estético, envolve o que está implícito nas atitudes em relação a ele mesmo e ao seu mundo. Já a visão de mundo (eidos) reflete a ordenação dos conceitos que vão subsidiar a elaboração conceitual das coisas, da natureza, de si mesmo e da sociedade. Assim, ethos reúne as características morais e estéticas de uma dada cultura, seus valores identitários, já o termo "visão de mundo" refere-se aos aspectos cognitivos e existenciais.

Dentre as principais marcas identitárias da cultura biomédica, podemos destacar duas que, apesar de já terem sido bastante discutidas e abordadas, ainda não se esgotaram. A primeira delas seria a hipervalorização da abordagem da doença no processo de cuidado, em contraponto à valoração dada ao sujeito que sofre. A outra seria o desequilíbrio entre o que se identifica como tecnicismo em detrimento da importância dos critérios intersubjetivos, interpretativos, intuitivos construídos a partir da experiência dos sujeitos e das trocas narrativas no encontro clínico (Ferreira, 2005). 
A discussão sobre humanização traz a possibilidade de relativização destas pretensas marcas identitárias, identificadas como ethos da assistência biomédica. Por meio da compilação e revisão de leituras e conceitos à luz desta discussão, tem-se a possibilidade de revisar alguns destes parâmetros, criticar seus contextos de aplicabilidade e, até mesmo, propor novas marcas.

Para ilustrar, podemos nos remeter à ingênua questão de que a prática clínica estaria sendo substituída pelo uso extensivo de tecnologias, em detrimento do encontro entre os sujeitos. Ou seja, as tecnologias, aqui representadas pelos exames de apoio diagnóstico, procedimentos e intervenções, estariam "tomando o lugar" da interação entre os diferentes atores mediada pelas trocas verbais, suas histórias e narrativas. Entretanto, esta linha de raciocínio é rapidamente relativizada quando reconhecemos que todos nós vivemos num mundo inexoravelmente mediado por técnicas e tecnologias.

As intervenções técnicas e tecnológicas, que atravessam nosso cotidiano, não são exclusivas do universo biomédico ou prerrogativa apenas presente nas ações de saúde. Utilizamos dispositivos técnicos de forma quase ilimitada e automática, sem problematizarmos quanto delegamos a estes dispositivos, como nos avisar de excessos (cinto de segurança) ou de lapsos possíveis e futuros (como o faz um despertador). Como situa Latour (1996), convivemos com técnicas de repressão/contenção, mas também com as de permissão/suporte (como o exemplo de um simples corrimão).

É importante pensar que tais utilizações não podem ser consideradas como boas ou más por si sós, ou ainda práticas sociais neutras, que não envolvem qualquer tipo de escolha. Elas se constituem, antes de tudo, como mediadoras de relações. Portanto, é importante destacar que o ponto principal não é o uso preponderante da tecnologia médica, mas qual o papel que esta tecnologia representa na ordem do cuidado construído e nas relações entre os sujeitos.

Desta forma, importa considerar, também, como tecnologias envolvidas na produção do cuidado e da gestão: o acolhimento, a escuta, a negociação, a interpretação de histórias e a aprendizagem com a experiência do outro. Tais tecnologias dizem respeito tanto à instituição quanto à equipe que aprende a aprender (Gomes et al., 2008; Caprara e Franco, 2006; Ayres, 2005).

Não estamos, portanto, diante de pares binários de oposição, ainda que culturalmente tal idéia seja constantemente reforçada. Quase somos condicionados a pensar de forma dicotômica ou excludente. Como se o domínio de técnicas e/ou tecnologias impedisse uma reflexão crítica ou se apenas sua aplicação garantisse o sucesso de um procedimento ou tratamento.

Neil Postman (1993), em seu livro Technopoly, ao refletir sobre a ideologia das máquinas e tecnologias médicas, destaca que, na experiência norte-americana, o que pode ser cobrado em termos monetários no sentido de ser reembolsado aos serviços de saúde são justamente os procedimentos técnicos, e não o tempo que os profissionais dispensam à pessoa doente.

Em termos de Brasil, não temos uma realidade tão diferente, tanto no SUS quanto na rede de saúde suplementar, o pagamento é calculado de maneira semelhante, isto é, por intervenção realizada. Nesta lógica, o que efetivamente interessa é a execução dos procedimentos, e não o modo como o atendimento é feito.

Desta forma, seria interessante pensar o que ocorreria se, num prontuário, tivesse um registro do tipo: acolhimento, mobilização de narrativas, produção de entendimento a partir de argumentos de prevenção e posturas de autocuidado, negociação quanto ao uso de medicação e de dieta.

Como expressar um valor para este grupo de procedimentos? Certamente não se trata de traduzi-los em valores monetários, apenas uma provocação a se refletir sobre como valorizar, na cultura biomédica (ultrapassando a noção de valorar), estas boas práticas que são também expressão de competência do profissional. Vale ainda pontuar que estas práticas correspondem a investimento profissional, pois demandam capacitações, aprimoramento e supervisão técnica.

Ao insistir nesta provocação, vale perguntar que prioridade é dada a este tipo de atendimento ao se montar, por exemplo, o quadro de profissionais para determinado serviço de saúde? A lógica vigente, tanto em serviços públicos, quanto privados para diferentes categorias profissionais é de quantificar o número de trabalhadores em relação ao número de pessoas atendidas. Tal cálculo baseia-se no máximo de atendimentos dentro de um tempo predeterminado a partir de uma rotina de tarefas estandardizadas. Este modelo de organização moderna do trabalho hospitalar foi historicamente 
construído e reproduzido observando padrões tayloristas de otimização de produtividade (Campos, 2001). Discutir isso significa não perder de vista que há um caráter macroestrutural que orienta e delimita um campo de práticas individuais.

\section{Considerações finais}

Consideramos que o emprego destas tecnologias comunicacionais não constitui apenas meios para se chegar a um fim determinado (seja ao diagnóstico, seja à adesão a certo tratamento/prescrição). Antes de tudo, são capazes de fortalecer e ajudar a instituir novos parâmetros para a produção de cuidados. Falamos de uma racionalidade comunicativa, e não instrumental, a ser posta em ação, seja do planejamento à realização do cuidado.

O desafio colocado é o de reconhecimento, aprendizagem e negociação com um outro que não é nosso espelho, mas um outro imbuído do tríplice estatuto de: indivíduo - detentor de direitos; sujeito detentor de capacidade de autonomia para fazer escolhas; pessoa - detentor de estoque cultural que Ihe confere uma identidade de referência no seu grupo social de pertencimento.

A humanização do cuidado passa por uma (re) definição da atitude subjacente do profissional em relação a ele mesmo e ao seu mundo, trata-se, portanto, de um ethos. O debate da humanização abre, também, uma arena de discursos sobre o cuidado, dessa forma, constitui um quadro de elaboração conceitual e valorativo, participa, assim, de uma visão de mundo sobre a saúde.

Contudo, a humanização das práticas de saúde só se consolidará como ethos ou como visão de mundo se for tomada como instituinte de práticas cotidianas e por elas sustentada; se alimentada por mecanismo de reprodução dentre os praticantes do cuidado (via formação acadêmica e pela força poderosa dos exemplos); se reconhecida como exercício que envolve uma expertise coletiva e individual, mas de modo algum inata.

Finalmente, ponderamos sobre os muitos limites deste artigo. A leitura habermasiana é densa e aqui foi simplificada para os moldes do espaço de debate proposto. Certamente, o texto teria se beneficiado se incluísse as proposições de Habermas sobre a ética do discurso. Por outro lado, o contraponto com Bourdieu poderia ser mais intensificado caso situássemos seu debate potente sobre a constituição de campos e a conformação estruturante dos habitus dos respectivos agentes. A discussão sobre a produção de identidades e ethos e sua expressão nas culturas institucionais dos serviços de saúde por si só demandaria um artigo inteiro, dada a profundidade que estes temas agregam nas ciências sociais.

Outro aspecto que mereceria maior reflexão é situar este debate diante das características que têm demarcado a paulatina implantação da PNH. A humanização, constituída como política pública de abrangência nacional, demarca singular diferença em face de muitas outras políticas de saúde. Não raro, políticas são construídas por indução do Estado e com incipiente entendimento junto aos atores sociais sobre suas diretrizes e estratégias. Geralmente, espera-se que seus quadros normativos sejam adequadamente e fielmente realizados. A PNH, ao contrário, aposta na construção cotidiana e criativa de interpretações e adaptações. Debater sobre os entendimentos construídos entre formuladores e agentes de implantação da política seria caminho rico, porém constituiria outro artigo. Assim, terminamos este texto abrindo novas pautas de estudo e diálogo, porque inconcluso e aberto à produção de outros devires reflexivos e vivenciais. 


\section{Colaboradores}

Suely Ferreira Deslandes responsabilizou-se pela idéia original do artigo, estruturação da discussão e reflexão inicial; Rosa Maria de Araújo Mitre responsabilizou-se pela formatação, análise e leitura crítica, com complementação da discussão.

\section{Referências}

AYRES, J.R.C.M. Hermenêutica e humanização das práticas de saúde. Cienc. Saude Colet., v.10, n.3, p.549-60, 2005.

O cuidado, os modos de ser (do) humano e as práticas de saúde. Saude Soc., v.13, n.3, p.16-29, 2004.

BOURDIEU, P. A economia das trocas lingüísticas. São Paulo: Edusp, 1996.

BRASIL. Ministério da Saúde. HumanizaSUS: Política Nacional de Humanização. Brasília: Ministério da Saúde, 2004.

CAMPOS, G.W.S. Gestión en salud: en defensa de la vida. Buenos Aires: Lugar Editorial, 2001.

CAPRARA, A.; FRANCO, A. Relação médico-paciente e humanização dos cuidados em saúde: limites, possibilidades, falácias. In: DESLANDES, S. (Org.). Humanização dos cuidados em saúde: conceitos, dilemas e práticas. Rio de Janeiro: Fiocruz, 2006. p. 85-108.

DESLANDES, S.F. Análise do discurso oficial sobre humanização da assistência hospitalar. Cienc. Saude Colet., v.9, n.1, p.7-14, 2004.

FERREIRA, F.C.B. Entre arabescos, luas e tâmaras: performances islâmicas em São Paulo. 2007. Tese (Doutorado) - Faculdade de Filosofia, Letras e Ciências Humanas, Universidade de São Paulo, São Paulo. 2007.

FERREIRA, J. O programa de humanização da saúde: dilemas entre o relacional e o técnico. Saude Soc., v.14, n.3, p.111-8, 2005.

FORTES, P.A.C. Ética, direitos dos usuários e políticas de humanização da atenção à saúde. Saude Soc., v.13, n.3, p.30-5, 2004.

GADAMER, H. Verdade e método: traços fundamentais de uma hermenêutica filosófica. Petrópolis: Vozes, 1997.

GEERTZ, C. A interpretação das culturas. Rio de Janeiro: Livros Técnicos e Científicos, 1989.

GOMES, A.M.A. et al. Fenomenologia, humanização e promoção da saúde: uma proposta de articulação. Saude Soc., v.17, n.1, p.143-52, 2008.

GRAEFF, B.P. O policial militar em tempos de mudança: ethos, conflitos e solidariedade na polícia militar do estado de São Paulo. 2006. Dissertação (Mestrado) - Programa de Pós-Graduação de Antropologia, Universidade de Braślia, Brasília. 2006.

HABERMAS, J. Theodor W. Adorno: pré-história da subjetividade e auto-afirmação selvagem. In: FREITAG, B.; ROUANET, S. (Orgs.). Habermas. São Paulo: Atica, 1990a. p.139-50.

Crítica conscientizante ou salvadora: a atualidade de Walter Benjamin. In: FREITAG, B.; ROUANET, S. (Orgs.). Habermas. São Paulo: Atica, 1990b. p.169-206. 1989.

Consciência moral e agir comunicativo. Rio de Janeiro: Tempo Brasileiro,

Dialética e hermenêutica. São Paulo: L\&PM, 1987. 
HOAS, J. Interacionismo simbólico. In: GIDDENS, A.; TURNER, J. (Orgs.). Teoria social hoje. São Paulo: Ed. Unesp, 1999. p.127-74.

LATOUR, B. Do humano nas técnicas. In: SCHEPS, R. (Org.). O império das técnicas. Campinas: Papirus, 1996. p.155-68.

POSTMAN, N. Technopoly: the surrender of culture to technology. New York: Vintage Books, 1993.

SCHLEIERMACHER, F.D.E. Hermenêutica: arte e técnica da interpretação. Petrópolis: Vozes, 1999.

SIEBENEICHLER, F.B. Jurgen Habermas: razão comunicativa e emancipação. Rio de Janeiro: Tempo Brasileiro, 1994.

STRAUSS, A. et al. The hospital and its negotiated order. In: FREIDSON, E. (Org.). The hospital in modern society. London: The Free Press of Glencoe, 1963. p.147-69.

THOMPSON, J.B. Ideologia e cultura moderna: teoria social crítica na era de comunicação de massa. Petrópolis: Vozes, 2000.

DESLANDES, S.F.; MITRE, R.M.A. Proceso comunicativo y humanización en salud. Interface - Comunic., Saude, Educ., v.13, supl.1, p.641-9, 2009.

El articulo abarca el proceso de comunicación comomuno de los desafíos afrontados en la humanización en salud. Reflexiona sobre potencialidades y requisitos para la producción de la acción comunicativa y apunta algunos obstáculos basándose en estudios antropológicos sobre la cultura biomédica. A partir del concepto de entendimiento, discute sobre los encuentros en salud y la relevancia de la validez y del reconocimiento del discurso de los diferentes actores. Indica la importancia de relativizar marcas de identidad asociadas a la cultura biomédica, desconstruir algunos conceptos, criticar sus contextos de aplicación e incluso proponer nuevas marcas por medio de la humanización. Se discute la relación entre las tecnologías biomédicas y el proceso de comunicación. El desafío que se plantea es el de aprender, reconocer y negociar con el otro que posee derechos, autonomía y bagaje cultural peculiares. Finalmente discute los esfuerzos teóricos para que la humanización de las prácticas en salud llegue a formar parte del ethos o visión del mundo de los profesionales de salud.

Palabras clave: Humanización de la asistencia. Comunicación. Comprehensión. Salud. 